\title{
Guidelines
}

\section{e Triaging Interventional Pain Procedures During COVID-19 or Related Elective Surgery Restrictions: Evidence-Informed Guidance from the American Society of Interventional Pain Physicians (ASIPP)}

\author{
Christopher Gharibo, MD¹, Amit Sharma, MD², Amol Soin, MD³, Shalini Shah, MD, \\ Kartic Rajput, MD PhD²3, Sudhir Diwan, MD, Ricardo Buenaventura, MD ${ }^{6}$, \\ Devi E. Nampiaparampil, MD7, Steve M. Aydin, DO ${ }^{8}$, Sanjay Bakshi, MD${ }^{9}$, Salahadin Abdi, \\ MD, PhD ${ }^{10}$, Sachin "Sunny" Jha, MD, MS"11, Harold J. Cordner, MD"12, Alan D. Kaye, MD, \\ $\mathrm{PhD}^{13}$, Alaa Abd-Elsayed, MD ${ }^{14}$, Kenneth D. Candido, MD ${ }^{15}$, Nebojsa Nick Knezevic, MD, \\ $\mathrm{PhD}^{16}$, Sairam Atluri, MD ${ }^{17}$, Bradley W. Wargo, DO ${ }^{18}$, Mahendra R. Sanapati, MD ${ }^{19}$, \\ Sukdeb Datta, MD20, Joshua A. Hirsch, MD ${ }^{21}$, and Laxmaiah Manchikanti, MD ${ }^{22}$
}

From: The American Society of Interventional Pain Physicians, Paducah, KY

See Full Author Affiliations on Pp. S197-S199

Address Correspondence: Christopher Gharibo, MD NYU Langone Health Medical Director of Pain Medicine 33 East 38th Street New York, NY, 10016 E-mail: christopher.gharibo@ nyulangone.org

Disclaimer: There was no external funding in the preparation of this manuscript.

Conflict of interest: Each author certifies that he or she, or a member of his or her immediate family, has no commercial association (i.e., consultancies, stock ownership, equity interest, patent/licensing arrangements, etc.) that might pose a conflict of interest in connection with the submitted manuscript.

Manuscript received: 07-18-2020 Accepted for publication: 07-23-2020

Free full manuscript: www.painphysicianjournal.com
Background: The COVID-19 pandemic has worsened the pain and suffering of chronic pain patients due to stoppage of "elective" interventional pain management and office visits across the United States. The reopening of America and restarting of interventional techniques and elective surgical procedures has started. Unfortunately, with resurgence in some states, restrictions are once again being imposed. In addition, even during the Phase II and III of reopening, chronic pain patients and interventional pain physicians have faced difficulties because of the priority selection of elective surgical procedures.

Chronic pain patients require high intensity care, specifically during a pandemic such as COVID-19. Consequently, it has become necessary to provide guidance for triaging interventional pain procedures, or related elective surgery restrictions during a pandemic.

Objectives: The aim of these guidelines is to provide education and guidance for physicians, healthcare administrators, the public and patients during the COVID-19 pandemic. Our goal is to restore the opportunity to receive appropriate care for our patients who may benefit from interventional techniques.

Methods: The American Society of Interventional Pain Physicians (ASIPP) has created the COVID-19 Task Force in order to provide guidance for triaging interventional pain procedures or related elective surgery restrictions to provide appropriate access to interventional pain management (IPM) procedures in par with other elective surgical procedures.

In developing the guidance, trustworthy standards and appropriate disclosures of conflicts of interest were applied with a section of a panel of experts from various regions, specialties, types of practices (private practice, community hospital and academic institutes) and groups. The literature pertaining to all aspects of COVID-19, specifically related to epidemiology, risk factors, complications, morbidity and mortality, and literature related to risk mitigation and stratification was reviewed. The evidence -- informed with the incorporation of the best available research and practice knowledge was utilized, instead of a simplified evidence-based approach. Consequently, these guidelines are considered evidence-informed with the incorporation of the best available research and practice knowledge.

Results: The Task Force defined the medical urgency of a case and developed an IPM acuity scale for elective IPM procedures with 3 tiers. These included urgent, emergency, and elective procedures. Examples of urgent and emergency procedures included new onset or exacerbation of complex regional pain syndrome (CRPS), acute trauma or acute exacerbation of degenerative or neurological disease resulting in impaired mobility and inability to perform activities of daily living Examples include painful rib fractures affecting oxygenation and post-dural puncture headaches 
limiting the ability to sit upright, stand and walk. In addition, emergency procedures include procedures to treat any severe or debilitating disease that prevents the patient from carrying out activities of daily living. Elective procedures were considered as any condition that is stable and can be safely managed with alternatives.

Limitations: COVID-19 continues to be an ongoing pandemic. When these recommendations were developed, different stages of reopening based on geographical regulations were in process. The pandemic continues to be dynamic creating every changing evidence-based guidance. Consequently, we provided evidence-informed guidance.

Conclusion: The COVID-19 pandemic has created unprecedented challenges in IPM creating needless suffering for pain patients. Many IPM procedures cannot be indefinitely postponed without adverse consequences. Chronic pain exacerbations are associated with marked functional declines and risks with alternative treatment modalities. They must be treated with the concern that they deserve. Clinicians must assess patients, local healthcare resources, and weigh the risks and benefits of a procedure against the risks of suffering from disabling pain and exposure to the COVID-19 virus.

Key words: Coronavirus, COVID-19, interventional pain management, COVID risk factors, elective surgeries, interventional techniques, chronic pain, immunosuppression

\section{Pain Physician 2020: 23:S183-S204}

\subsection{INTRODUCTION}

COVID-19 has made a dramatic impact on the economy, society and healthcare, particularly in the interventional pain management (IPM) community. At the height of the COVID-19 pandemic, elective interventional techniques and new patient visits were eliminated. This resulted in a significant stress placed upon interventional pain physicians and their practices, exacerbating burnout (1). A survey conducted by American Society of Interventional Pain Physicians (ASIPP) revealed the devastating effects of COVID-19 on IPM, with $98 \%$ of the practicing physicians being affected, $54 \%$ with new burnout secondary to COVID-19, 55\% attempting to retire from medical practice, $91 \%$ affected financially, $66 \%$ with a negative outlook of the future, $73 \%$ stressed due to electronic medical records, $67 \%$ stressed due to in-house billing, and, finally, $80 \%$ of the physicians performing interventional techniques (1). Thus, the COVID-19 pandemic has created unprecedented challenges to society-in-general and the health care system in-particular.

As the lockdown progressed, economic and political pressure surfaced to relax "shelter-in-place," public health orders for multiple industries including health care (2). However, during the lockdown and even with the phased-in re-opening there have been multiple practices of the priority-based scheduling interventional pain procedures may have been delayed. In the United States, a prerequisite for health care facilities to return to interventional pain procedures, is robust testing for active infection for at-risk health care professionals, and risk stratification $(3,4)$. With prioritiza- tion as criteria, health care facilities are opening, IPM physicians have not been able to perform their cases at the same pace as other specialties.

\subsection{Impact of Chronic Pain and COVID-19}

The impact of chronic pain on society is not only enormous, but also disproportionate to any other condition in causing disability and economic toll (5-12). Among the conditions treated by interventional pain physicians, chronic persistent spinal pain lasting longer than one-year is reported in $25 \%$ to $60 \%$ of all patients (5-7). Freburger et al (11) in an assessment of the rising prevalence of chronic low back pain from 1992 to 2006, showed that the prevalence of chronic, impairing low back pain rose significantly over the 14-year interval from $3.9 \%$ in 1992 to $10.2 \%$ in 2006 . Blyth et al (12) assessed the global burden of musculoskeletal pain and identified key gaps in the understanding of musculoskeletal pain. Health care expenditures have been escalating over the years with estimates of US health care spending reaching $\$ 3.66$ trillion in 2018 . Further, health care expenditures were already expected to continue to grow at a rate of 5.5\% from 2018 to 2027 (13). In 2018, the cost of health care per capita in the United States was $\$ 11,212$, which is expected to increase in 2019 to $\$ 12,194$, without including the impact of COVID-19. Specific to IPM, Dielman et al (8) performed 2 studies estimating health care spending in the United States for various conditions. For low back pain they estimated a spending of a total of $\$ 183$ billion, with $\$ 87.6$ billion in low back and neck pain and on musculoskeletal disorders of $\$ 95.5$ billion in 2013. However, estimates for in 
2016 showed health care spending increasing from an estimated $\$ 1.5$ trillion in 1996 or $\$ 5,259$ per person to an estimated $\$ 3.1$ trillion and per person cost of $\$ 9,655$ (8). Further, they also showed that for musculoskeletal disorders spending was second highest with $\$ 264.3$ billion in 2016 compared to $\$ 183$ billion in 2013, with a $44.4 \%$ increase (8).

Over the years, exploding health care costs have been identified for management of spinal pain and chronic pain, including over-the-counter medications all the way up to complex surgical fusions. However, in recent years, the utilization of interventional techniques, as well as opioid therapy has shown a flattening of utilization of most modalities even though there are some modalities with increases and even a true decline for some services. Ironically, the utilization of opioids, as well as interventional techniques simultaneously started declining, indicating various issues related to control of all types of health care modalities instead of improving non-opioid care $(5-7,14-25)$. A recent analysis of the growth of utilization of interventional techniques in managing chronic pain in the Medicare population (14) showed an overall decline in utilization from 2009 to 2018 of $6.7 \%$, with an annual decline of $0.8 \%$ per 100,000 fee-for-service Medicare population. Total opioid prescriptions, morphine milligram equivalents (MME) per person, and opioidrelated deaths have declined substantially (23). Now, prescription-related opioid deaths at 14,975 in 2018 is equivalent to deaths of heroin of 14,996 and cocaine of 14,666 . Further, the number of opioid prescriptions reduced from 251.8 million in 2013 to 168.8 million in 2018. The major issue has been the multitude of other synthetic narcotics such as fentanyl with total deaths in 2018 of $31,335(15,22)$.

Chronic pain is disabling; however, if left untreated, it can also have serious consequences, the extent of which may not yet be fully appreciated. It has been shown that patients with chronic pain who cannot get appropriate treatment reported that pain interferes with their basic function, with $50 \%$ reported that it leads to feelings of depression, while $35 \%$ reported suicidal ideation (26). This study also reported significant changes in pain intensity levels, emotional suffering and disability in pain patients with a wait time of 3 months (26).

\subsection{Impact of Delayed Treatment}

The inability to consult with an interventional pain specialist may lead some pain patients to seek out alter- nate and possibly inappropriate or harmful treatments such as elevated doses of nonsteroidal anti-inflammatory drugs (NSAIDs), illicit drugs and escalating opioid use (27). The COVID-19 pandemic has disrupted pain care and life as we are accustomed to living across the globe. In an effort to prevent patients and staff from being infected with COVID-19 and to divert valuable healthcare resources to potentially fatal cases of the COVID-19 infection, elective, routine, and non-urgent care were halted in secondary and tertiary centers and special protocols were introduced for primary care, long-term residential care, hospices, and other settings (27). However, many patients with chronic pain or at risk for developing chronic pain conditions were also those at high risk for COVID-19: older patients, those with chronic underlying diseases, and those with limited access to healthcare (27). Thus, the individuals who were most likely to suffer from their chronic pain and needed treatment were also most likely to be asked to avoid in-person clinical visits and defer their interventional pain procedures to protect them from possible viral transmission and preserve resources.

Since pain is the reason for $45 \%$ of visits to emergency departments (28), the influx of pain patients to emergency departments has overwhelmed some hospitals, ramped up the need for personal protective equipment (PPE) independent of the COVID-19 units, and exposed healthcare professionals to the risk of treating patients with unknown COVID status. Thus, the treatment of pain is vital to the patient's health. An individual with an acute lumbosacral radiculopathy may be incapacitated as well as treated with escalating doses of opioids, oral steroids or even surgery although such a condition could and would likely be treated with a common intervention such as an epidural injection. The pain of an individual with a new onset or exacerbation of CRPS of the upper or lower extremities may be best treated with a single sympathetic block as opposed to alternative treatment options that may not or have not been as effective. Chronic pain can suppress the immune system, which can adversely impact survival in certain populations, such as cancer pain patients (29). Patients with intrathecal drug infusion systems may suffer distressing or life-threatening withdrawal symptoms, not to mention painful symptoms if the pump cannot be refilled on time. In addition, the pump batteries may die leading to the need for replacement, which is costly. The full consequences of COVID-19 will likely not be fully assessable until the end of the pandemic. 


\subsection{Consequences of Inadequate Treatment}

In many patients, the only option is continuing opioids with telehealth follow-up visits, although initiation of opioids or evaluation of new patients is not recommended. Escalation of opioid doses is also crucial considering multiple available guidelines and recommendations, even though these have been relaxed to a great extent during the pandemic (30). However, opioids regulate the immune system in several aspects. It is known that the activation of opioid receptors leads to a reduction in the number of macrophages, a decrease in phagocytic activity and accelerated apoptosis. Consequently, pain as well as opioids both have significant effects on the immune system, subjecting the patients to further reductions in immunity and increasing the risk for infections and delayed recovery.

There have been global, dynamic challenges faced by healthcare systems to the evolving breakout of $\mathrm{CO}$ VID-19 that have resulted in elective surgery bans with no pre-determined end in sight. Despite the urgent and emergency need of many Americans for continuous pain care, essential IPM procedures have not been discussed in the same context as other forms of pain care, for example, treatment of patients on chronic opioid therapy. Nor has IPM been described in the same manner as for other surgical procedures wherein their acuity, functional impact and disease progression was assessed.

\subsection{State of Guidance}

The Centers for Disease Control and Prevention (CDC) have issued a framework for the care of nonCOVID-19 patients during the pandemic based on a matrix of the risk of harm to the patient balanced against the risk of harm to the community $(31,32)$. For example, strokes and heart attacks should be addressed immediately, although care may in some cases be diverted to a facility less impacted by the pandemic, while physical therapy (even if it may result in patient harm) should be delivered remotely if possible and only in person if there is no risk to the community. Elective procedures that can be delayed without risk to the patient should be postponed. This guidance must be individualized for certain specific cases, for example, in patients with serious underlying diseases or in those with no access to telehealth options (32).

Despite the tremendous burden that chronic pain represents to American citizens as well as national healthcare and the fact that many chronic pain patients require continuous care that is especially vital during times of crisis, there is no guidance on how to prioritize IPM for these patients in times of dynamic and complicated risk-benefit analysis. Delaying interventional pain treatments for the treatment of severe acute pain or acute or chronic pain exacerbations risks devastating functional impairments that predisposes the patient to further morbidities, unnecessary surgery or even mortality.

Multiple guidelines have been published in the past by various organizations (33-35). Shah et al (3) addressed the risk stratification during COVID-19 for return to interventional pain practices; however, thus far the role of interventional techniques during the pandemic or resurgence has otherwise not been addressed. Consequently, chronic pain patients may continue to suffer without appropriate treatment.

Thus, overlooking medically necessary and indicated care for chronic pain patients can have negative impacts on health, well-being, emotional stability, function, and quality of life $(27-29,36)$. Consequently, pain specialists must balance the needs for pain control against reasonable concern and precautions related to coronavirus and the COVID-19 pandemic. Membership has requested ASIPP to frame guidelines determining the status of interventional pain procedures based on their need as elective urgent or emergency. The contextual, tiered framework has been advanced by the Centers for Medicare and Medicaid Services (CMS) in broad terms to help differentiate low, intermediate, and high-acuity treatments or services $(31,32)$. In addition, multiple organizations also have established guidance for their own specialties $(33-35,37,38)$. Further, multiple states have utilized stricter guidelines or the guidelines developed by specialty societies.

Multiple guidelines have been published by ASIPP in performing various types of interventional techniques, regenerative medicine, opioids in chronic non-cancer pain, antithrombotic therapy, sedation, and facet joint interventions (3,5-7). More recently, pertinent to the subject of the COVID-19 pandemic, ASIPP has developed evidence-informed risk mitigation and stratification guidelines during COVID-19 for return to interventional pain practice. Thus, ASIPP has been at the forefront of guideline development for the safe and responsible use of interventional techniques and opioids (3,5-7). Consequently, to better serve chronic pain patients, ASIPP established a COVID-19 Task Force to develop triaging interventional pain procedures or related elective surgery restrictions. 


\subsection{Methods}

Chronic pain is defined as a complex and multifactorial disease process with numerous treatment modalities applied in the management of the problem. Additionally, the growing social, economic and COVID-19 pandemic costs have created a huge influence on medical decision making. While interventional techniques and opioids are the mainstays of treatment, there are multiple other adjuvant modalities being provided for the management of chronic pain by interventional pain physicians.

\subsection{Rationale}

IPM has been defined as the discipline of medicine devoted to the diagnosis and treatment of pain-related disorders principally with the application of interventional techniques in managing subacute, chronic, persistent, and intractable pain, independently or in conjunction with other modalities of treatment (www. cms.hhs.gov/transmittals/Downloads/r1779b3.pdf Accessed 5/28/2020). IPM techniques have been defined as minimally invasive procedures including percutaneous precision needle placement of drugs in targeted areas or ablation of targeted nerves; surgical techniques such as laser and endoscopic discectomy; and the placement of intrathecal infusion pumps and spinal cord stimulators for the diagnosis and management of chronic, persistent, or intractable pain ( http://medpac.gov/docs/ default-source/reports/december-2001-report-to-thecongress-paying-for-interventional-pain-services-inambulatory-settings.pdf?sfvrsn=0 Accessed 5/28/2020).

\subsection{Objectives:}

The ASIPP COVID-19 Task Force was established to develop guidance for triaging interventional pain procedures or related elective surgery restrictions and to provide a context and strategy for elective interventional procedures and interventional techniques including surgical procedures related to chronic pain. Fundamental to this task are the overarching considerations of increasing risk without treatment, risk stratification, and development of safe strategies to develop guidance for triaging interventional pain procedures during COVID-19 or related elective surgery restrictions. Thus, development of guidance involves reducing harms to patients, health care professionals, and the health care system, and improving quality of care with pain relief to improve functional status. Thus, identification of these factors is very important in development of the guidelines and taking into account the impact of COVID on patient population, drug therapy, lack of treatment, resource utilization, and adverse effects of elective surgery restrictions on IPM practices, defining medical urgency of a case, developing IPM acuity scale, and forwarding those recommendations to the membership.

The guidance is not standard of care. Clinicians must base their decisions on an assessment of individual risks versus benefits and understand that, ultimately, these recommendations are dynamic and situational. As more evidence and understanding of COVID-19 pandemic emerges, more precise recommendations may follow. In addition, it is crucial to understand that recommendations made here may or may not be appropriate for every setting and location. Thus, it is crucial to follow local state and federal regulations and take an individualized approach.

To perform urgent and emergency procedures, it is important to stratify or rank patients for their relative risk of contracting COVID-19 or having a poor outcome in the event of an infection. A risk stratification scoring system has been developed to provide a rapid objective assessment of individual patients, as shown in Fig. 1 and Table 1.

\subsection{Adherence to Trustworthy Standards}

In preparation of these guidelines for triaging interventional pain procedures during the COVID-19 pandemic for return to interventional pain practice, the standards from the Institute of Medicine (IOM) and the National Guideline Clearinghouse Extent Adherence to Trustworthy Standards (NEATS) were followed (39-41). The NEATS instrument was developed and tested as a tool to be used by the trained staff at the Agency for Healthcare Research and Quality (AHRQ) National Guideline Clearinghouse to provide assessment focused on adherence.

\subsubsection{Disclosure of Guideline Funding Source}

Comprehensive evidence-informed guidelines for risk mitigation/stratification during COVID-19 for return to interventional pain practice were commissioned, prepared, edited, and endorsed by ASIPP without external funding.

\subsubsection{Disclosure and Management of Financial Conflicts of Interests}

Potential conflicts of interest for all panel members within the last 5 years were evaluated prior to the finalizing of these guidelines. Conflicts of interests extended beyond financial relationships, including per- 


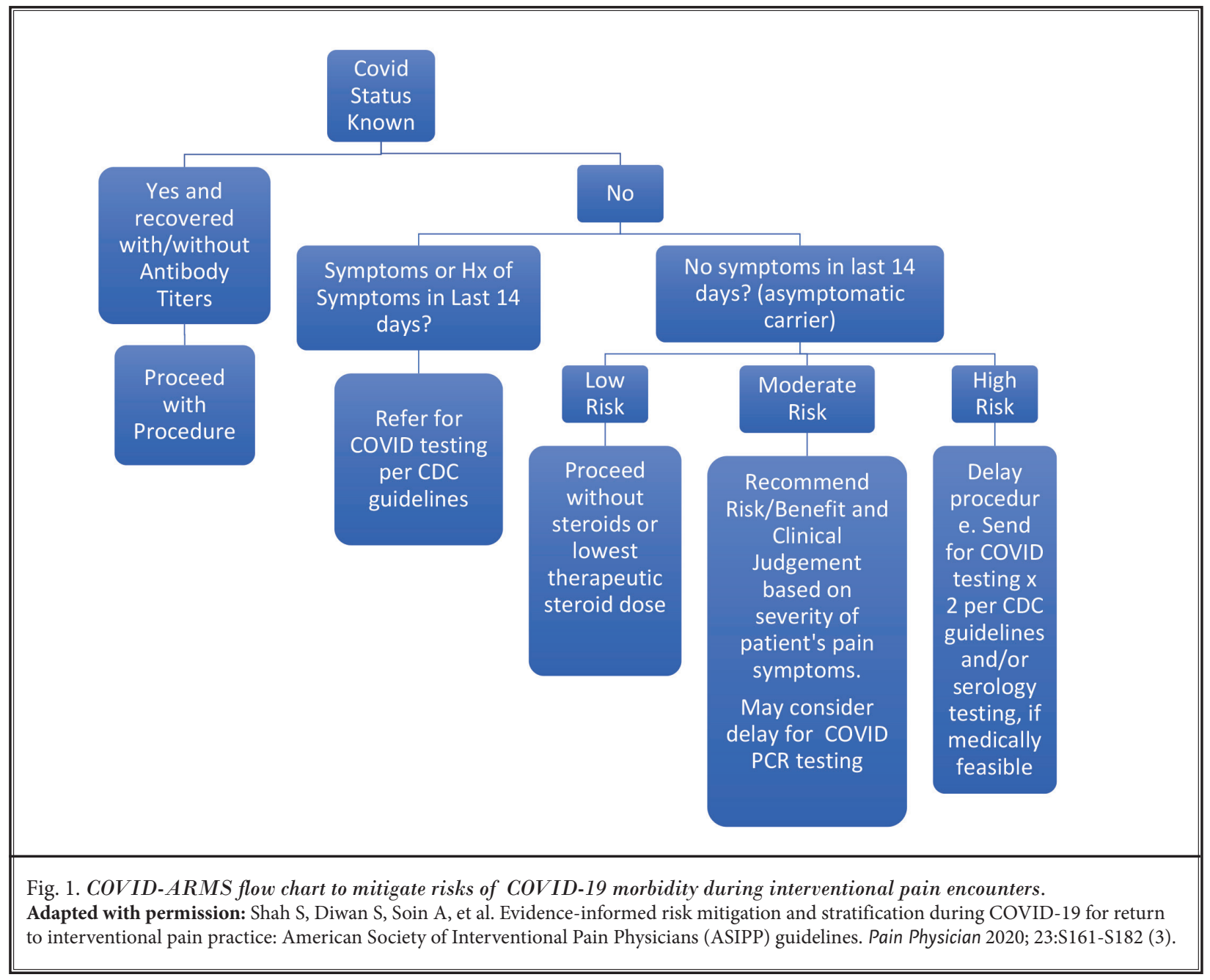

sonal experience, practice patterns, academic interests, and promotions. The panel members with potential conflicts were recused from discussion or preparation of the guidelines in which they had conflicts of interest, and these members agreed not to discuss any aspect of a given guideline with the related industry before data publication.

\subsubsection{Composition of Guideline Development Group}

A panel of experts in interventional techniques, opioid therapy and administrative expertise from various medical fields, convened by ASIPP, reviewed the evidence and formulated recommendations for triaging interventional pain procedures during COVID-19 for return to interventional pain practice. Overall, the panel provided a broad representation of academic and non-academic clinical practitioners with interest and expertise in IPM.

\subsection{Evidence Review}

These guidelines were developed utilizing consensus among the panel members after they had reviewed all published literature concerning the use and safety of interventional techniques during and after the COVID-19 pandemic. The recommendations have been developed using the principles of best evidence synthesis developed by the Cochrane Review, incorporating multiple guidelines modified by ASIPP (42). In this manuscript, due to the lack of randomized controlled trials or even observational studies related to IPM and COVID-19, and due to the nature of the subject and ongoing evolutionary changes, an evidence-informed strategy was utilized instead of evidence-based strategy. 
Table 1. COVID-ARMS risk stratification of patients presenting for interventional pain procedures for decreasing morbidity of COVID-19 (points appear in brackets).

If Patient Residence status is Nursing Home or Assisted Living Facility or Incarceration during the past 30 days, consider as HIGH-RISK Patient. If not, follow below table for risk stratification.

\begin{tabular}{|c|c|c|c|}
\hline Risk Factor & Low Risk & Moderate Risk & High Risk \\
\hline Age (years) & $\begin{array}{l}45-64 \text { years } \\
{[1]}\end{array}$ & $\begin{array}{l}65-74 \text { years } \\
{[2]}\end{array}$ & $\begin{array}{l}\geq 75 \text { years } \\
{[3]}\end{array}$ \\
\hline Pulmonary & $\begin{array}{l}\text { None } \\
{[0]}\end{array}$ & $\begin{array}{l}\text { Mild intermittent asthma } \\
\text { [2] }\end{array}$ & $\begin{array}{l}\text { Chronic lung condition, i.e., moderate to severe } \\
\text { asthma, COPD } \\
{[3]}\end{array}$ \\
\hline Cardiovascular & $\begin{array}{l}\text { None } \\
{[0]}\end{array}$ & $\begin{array}{l}\text { HTN or CAD } \\
{[2]}\end{array}$ & $\begin{array}{l}\mathrm{HTN}+\mathrm{CAD} \\
\mathrm{HTN}+\mathrm{CHF} \\
\mathrm{HTN}+\mathrm{CAD}+\mathrm{CHF} \\
\text { CHF alone } \\
{[3]}\end{array}$ \\
\hline Obesity & $\begin{array}{l}\text { BMI 24.9-29.9 } \\
{[1]}\end{array}$ & $\begin{array}{l}\text { BMI 30.0-39.9 } \\
{[2]}\end{array}$ & $\begin{array}{l}\mathrm{BMI}>=40 \\
{[3]}\end{array}$ \\
\hline $\begin{array}{l}\text { Diabetes (A1C) } \\
\text { BGM (mg/dl) } \\
\text { (Consider finger-stick BGM if } \\
\text { A1C is not available) }\end{array}$ & $\begin{array}{l}5.8-6.49 \mathrm{or} \\
100-120 \mathrm{mg} / \mathrm{dl} \\
{[1]}\end{array}$ & $\begin{array}{l}6.5-8.49 \mathrm{or} \\
120-160 \mathrm{mg} / \mathrm{dl} \\
{[2]}\end{array}$ & $\begin{array}{l}>=8.5 \mathrm{or} \\
>160 \mathrm{mg} / \mathrm{dl} \\
{[3]}\end{array}$ \\
\hline Renal & $\begin{array}{l}\text { None } \\
{[0]}\end{array}$ & $\begin{array}{l}\text { Acute or chronic renal } \\
\text { insufficiency } \\
{[2]}\end{array}$ & $\begin{array}{l}\text { Chronic renal insufficiency on dialysis } \\
\text { [3] }\end{array}$ \\
\hline Hepatic & $\begin{array}{l}\text { None } \\
{[0]}\end{array}$ & $\begin{array}{l}\text { Chronic hepatitis } \\
\text { [2] }\end{array}$ & $\begin{array}{l}\text { Cirrhosis } \\
{[3]}\end{array}$ \\
\hline Immuno-compromised state & $\begin{array}{l}\text { None } \\
{[0]}\end{array}$ & $\begin{array}{l}1 \text { stable condition } \\
{[2]}\end{array}$ & $\begin{array}{l}\text { The presence of ANY: } \\
\text { Cancer (active treatment) } \\
\text { Bone marrow/organ transplantation } \\
\text { Immune deficiencies } \\
\text { Poorly controlled HIV/AIDS } \\
\text { Chronic steroid use } \\
\text { [3] }\end{array}$ \\
\hline
\end{tabular}

${ }_{* *}$ The scoring number for risk factor is listed in parentheses. This number indicates the points for that condition.

Low Risk: $<=7$ points Moderate Risk: 8-14 points High Risk: $>=15$ points

$\mathrm{BGM}=$ blood glucose meter; $\mathrm{BMI}=$ body mass index; $\mathrm{CAD}=$ coronary artery disease; $\mathrm{CHF}=$ congestive heart failure; $\mathrm{COPD}=$ chronic obstructive pulmonary disease; HTN = hypertension

Adapted with permission: Shah S, Diwan S, Soin A, et al. Evidence-informed risk mitigation and stratification during covid-19 for return to interventional pain practice: American Society of Interventional Pain Physicians (ASIPP) guidelines. Pain Physician 2020; 23:S161-S182(3).

The evidence-based medicine process relies on quantitative research studies that provide the highest levels of evidence for decisions about interventions and other aspects including diagnosis, side effects, and prevalence (43). However, the evidence-based approach is also considered too restrictive and that decisionmaking for individual patients, for an organization, for a population, or on various subjects without substantial evidence and evolving in epidemiology must rely on additional forms of evidence that are much more inclusive and less rigid.

Woodbury and Kuhnke (43) proposed that in- formation used to make clinical decisions in clinical practice should include more than evidence collected with a singular goal of reducing bias in interventional research and should include a variety of sources of research information that addresses a wider range of goals. Thus, Estabrooks (44) suggested that clinicians add their own conventional wisdom and common sense in the form of knowledge gained from qualitative and sometimes quantitative studies. Even though the term "evidence-informed" is used infrequently compared to evidence-based, the distinction and advantages have been clarified by Woodbury and Kuhnke (43). A further 
nuance has been provided by, Miles and Loughlin (45) who promoted using the term "evidence-informed" to indicate that the process be person-centered rather than focused on the signs of reducing the quantitative evidence, which, they claim has taken humanity out of clinical practice. Further, multiple international and national organizations promote the idea of evidenceinformed decision-making, such as the World Health Organization (WHO) refers to evidence-informed policymaking (46), while the Canadian Institute for Health Research also refers to evidence-informed decision making (47). Even though some utilize evidence-based and evidence-informed interchangeably, more recently, with a movement towards real world evidence, it appears that evidence-informed may be a more appropriate term with more flexibility regarding the nature of the evidence and its use. Thus, it may be considered that evidence-informed medicine extends beyond the definition of evidence-based medicine with the inclusion of real world evidence in real-world settings.

\subsubsection{Grading or Rating the Quality or Strength of Evidence}

The grading of evidence is based on randomized controlled trials, observational studies, and other clinical reports. In addition, systematic reviews and metaanalyses were utilized. The grading of evidence based on ASIPP guidelines is shown in Table 2 (42).
This grading system specifies levels of scientific evidence and offers an approach to grading the quality of evidence and secondarily the strength of recommendations. AHRQ has recommended a similar approach to the strength of a recommendation $(40,41)$.

\subsubsection{Rating or Grading the Strength of Recommendations}

IOM standards demand that for each recommendation, a rating of the strength of the recommendation related to benefits and harms, available evidence, and the confidence in the underlying evidence should be provided. To meet appropriate standards, the rating schemes recommended by NEATS were utilized as shown in Table 3 (40).

\subsection{Results}

All the relevant studies were identified by search of multiple databases with the search focusing on COVID-19 related elective surgery recommendations, including the CDC and multiple states, epidemiology, pathophysiology, complications, testing and guidance on prevention in the perioperative period. There were no manuscripts available describing specific evidencebased or evidence-informed guidance for triaging interventional pain procedures during COVID-19 or related elective surgery restrictions. However, related to the complex nature of the problem, in a pandemic

Table 2. Qualitative modified approach to grading of evidence.

\begin{tabular}{|l|l|l||}
\hline Level I & Strong & $\begin{array}{l}\text { Evidence obtained from multiple relevant high-quality randomized controlled trials for effectiveness } \\
\text { or } \\
\text { Evidence obtained from multiple relevant high quality observational studies or large case series for } \\
\text { assessment of preventive measures, adverse consequences, and effectiveness of other measures }\end{array}$ \\
\hline Level II & Moderate & $\begin{array}{l}\text { Evidence obtained from at least one relevant high-quality randomized controlled trial or multiple relevant } \\
\text { moderate or low-quality randomized controlled trials } \\
\text { or } \\
\text { Evidence obtained from at least 2 high-quality relevant observational studies or large case series for } \\
\text { assessment of preventive measures, adverse consequences, and effectiveness of other measures. }\end{array}$ \\
\hline Level III & Fair & $\begin{array}{l}\text { Evidence obtained from at least one relevant high-quality nonrandomized trial or observational study with } \\
\text { multiple moderate or low-quality observational studies } \\
\text { or } \\
\text { At least one high-quality relevant observational studies or large case series for assessment of preventive } \\
\text { measures, adverse consequences, and effectiveness of other measures. }\end{array}$ \\
\hline Level IV & Limited & $\begin{array}{l}\text { Evidence obtained from multiple moderate or low-quality relevant observational studies } \\
\text { or } \\
\text { Evidence obtained from moderate quality observational studies or large case series for assessment of } \\
\text { preventive measures, adverse consequences, and effectiveness of other measures. }\end{array}$ \\
\hline Level V & Consensus based & $\begin{array}{l}\text { Opinion or consensus of large group of clinicians and/or scientists for effectiveness as well as to assess } \\
\text { preventive measures, adverse consequences, and effectiveness of other measures. }\end{array}$ \\
\hline
\end{tabular}

Modified from: Manchikanti et al. A modified approach to grading of evidence. Pain Physician 2014; 17:E319-E325 (84). 
Table 3. Guide for strength of recommendations.

\begin{tabular}{|l|l||}
\hline \hline Rating for Strength of Recommendation \\
\hline Strong & $\begin{array}{l}\text { There is high confidence that the recommendation reflects best practice. This is based on: a) strong evidence for a true net } \\
\text { effect (e.g., benefits exceed harms); b) consistent results, with no or minor exceptions; c) minor or no concerns about study } \\
\text { quality; and/or d) the extent the panelists' agreement. Other compelling considerations (discussed in the guideline's literature } \\
\text { review and analyses) may also warrant a strong recommendation. }\end{array}$ \\
\hline Moderate & $\begin{array}{l}\text { There is moderate confidence that the recommendation reflects best practice. This is based on: a) good evidence for a true } \\
\text { net effect (e.g. benefits exceed harms); b) consistent results, with minor and/or few exceptions; c) minor and/or few concerns } \\
\text { about study quality; and/or d) the extent of panelists' agreement. Other compelling considerations (discussed in the guideline's } \\
\text { literature review and analyses) may also warrant a moderate recommendation. }\end{array}$ \\
\hline Weak & $\begin{array}{l}\text { There is some confidence that the recommendation offers the best current guidance for practice. This is based on: a) limited } \\
\text { evidence for a true net effect (e.g., benefits exceed harms); b) consistent results, but with important exceptions; c) concerns } \\
\text { about study quality; and/or d) the extent of panelists' agreement. Other considerations (discussed in the guideline's literature } \\
\text { review and analyses) may also warrant a weak recommendation. }\end{array}$ \\
\hline \hline
\end{tabular}

Source: National Guideline Clearinghouse Extent Adherence to Trustworthy Standards (NEATS) instrument (84).

setting with lockdowns and resurgence without much guidance available, the present assessment was unable to apply evidence-based principles with grading of evidence and the strength of recommendations as described previously in ASIPP guidelines (44-47).

Consequently, our study has utilized an informed approach including the consensus-based decision-making for evidence synthesis and consensus-based criteria and provided recommendations based on all types of evidence.

\subsection{Impact of COVID-19 on Chronic Pain Patients}

The lack of specialists and limited procedures being performed have meant that fewer patients are treated or that formerly routine procedures such as a steroid injections necessitate complicated clinical logistics and may arouse tremendous anxiety in patients (33). Telehealth visits may be helpful for some high-functioning patients with stable chronic pain (48). However, there are no effective electronic alternatives to the interventional techniques or manual therapies that enable some patients to perform their basic activities of daily living (33). These patients are in particularly dire straits because, with the shutdown and the emphasis on social distancing, they cannot rely on others to help them obtain food or other necessities. Moreover, some patients, such as those requiring regular refills of their intrathecal pumps, are at increased risk of sudden death from the abrupt depletion and withdrawal of the medications in their pumps.

\subsection{Impact of Elective Surgery Restrictions on Pain Patients}

Chronic pain causes significant physical and emo- tional suffering, limits everyday activities, and markedly reduces the quality of life. People suffering from subacute or chronic pain face challenges in getting through their daily chores, work, and family responsibilities. IPM has emerged as a powerful tool to help address the symptomatic burden these people face when conventional treatments, such as physical therapy, chiropractic adjustments, pharmacotherapy, surgery and even alternative treatment such as acupuncture have been exhausted. The COVID-19 pandemic has put a screeching halt to these adjuvants and restrictions related to social distancing have led to shutting down of physical therapy centers, chiropractic clinics, and other healthcare services.

Even maintaining a pharmacological regimen could be challenging as many pain physicians were forced to restrict their practices due to state-guided restrictions and lack of support staff. With widespread school closures, many clinical support personnel had to take time off from work to care for their children. Moreover, patients often canceled their regular appointments for fear of exposure to the infection. Telemedicine and eHealth approaches are being developed and tested in a gradual fashion, there are still barriers to the acceptance and adoption of telehealth (27).

Physicians and other healthcare providers face a myriad of problems related to caregiver services. In two-parent households where both parents must work outside the home (ex. married doctors), child care is often an issue. Because daycare centers and schools are closed, one parent may have to withdraw from the workforce. This problem is often magnified in singleparent and divorced parent households. In many situations, physicians and other healthcare providers are 
caregivers for elderly or disabled parents living at home. Some of these clinicians leave the workforce because they cannot find adequate home health services due to the shutdown. Single and divorced pet owners may also face difficulties. The lack of caregiver services, due to a combination of COVID and the shutdown, has resulted in a decrease in the number of available healthcare workers. Because medical care is often delivered by teams rather than individuals (e.g., one physician, one nurse, one medical assistant and one receptionist), the absence of a team member creates an undue burden on the rest of the team and can also translate to inefficiencies in patient care whether virtual or face-to-face.

Further, people working virtually from home also experienced repetitive strain injuries related to poor ergonomics and the lack of appropriate workstations at home.

As indoor family time has increased with the pandemic, more people have suffered acute exacerbations of their chronic spinal conditions or suffered new injuries to the spine attempting to fix their cars, houses, increasing indoor or outdoor exercise routines, or simply playing with their children. Unable to obtain appointments with their primary care doctors, physical therapists, or chiropractors and shutting of urgent care centers or emergency departments, these patients had to manage their new or exacerbated painful conditions with little support. Telemedicine platforms and radiological scans could be helpful in identifying the underlying cause of pain in many such clinical situations, but treatment options were limited. Conservative courses of treatment, such as physical therapy, were often precluded. Pharmacological therapy became an important option, but the new or ongoing use of NSAIDs, steroids, and opioids (and possibly at higher doses) has also been a matter of concern. More recent studies have shown an increase in substance abuse, opioid and non-opioid overdoses during the COVID pandemic (49-58). In addition, multiple aspects of psychosocial impact of $\mathrm{CO}$ VID-19 (59) with potential implications for individuals with substance use disorders (60-65). In fact, Becker and Fiellin (63) described coalition effect of COVID-19 and the opioid crisis. The effects also entered into social dynamics with descriptions of how fighting one pandemic can deepen another one described as deaths of despair with increasing deaths and mortality in mid-life among white non-Hispanic Americans in the 21st century (66).

Oncology patients were particularly hard hit, as there were no clear guidelines on safe and appropriate care (35). Cancer patients appear to be at elevated risk for severe and even critical responses to COVID-19, particularly those who were undergoing or recently completed chemotherapy. Cancer patients, being at high risk for potentially life-threatening COVID-19 infections, are often discouraged from travelling to receive care.

It is well known that IPM is an effective and valuable option for many patients experiencing sudden exacerbations in pain. Interventional options in many cases may improve function and eliminate or reduce the need for opioids (67). Opioids (68), uncontrolled pain (69), and steroids $(5,70-75)$ can all suppress the immune system. IPM with local anesthetics or reduced or steroids $(3,5,70-75)$ would be considered "an alternative." A clear stratification of specific IPM techniques as we propose along with a cautious approach to deliver these modalities at all levels, i.e., office-based practices, ambulatory surgery centers, and hospitals, would serve our specialty and our patients better in the future.

\subsection{Impact of Elective Surgery Restrictions on IPM Practices}

Almost every doctor treats pain in some form. IPM physicians are called to treat some of the most challenging painful conditions when conservative treatment modalities have been exhausted and surgical options are either not applicable or not recommended. The initial ban on elective surgery combined with the nationwide "lockdown" and other pandemic-related restrictions had serious consequences for chronic pain practices. There is a misperception in the medical community and by some ambulatory surgery centers (ASCs) and hospital administrators that "most" IPM services are elective. As a result, across the country, some hospitals and ambulatory care centers closed their IPM services under the justifications that they are purely elective. Often, in these settings, interventional pain physicians or their representatives were not part of the discussion. As a result, some chronic pain patients who had come to rely on regular IPM care practices for their basic function found that their care was not available. Since the COVID-19 pandemic and related societal shutdowns encompassed many unknown variables-such as how long it would last and how severe it would get-pain patients struggled and braced themselves for dealing with untreated and otherwise untreatable pain for an indeterminate amount of time. Many worried about the long-term effects of untreated pain beyond their present suffering and on their ability to attend to basic needs such as self-care, food shopping and preparation, 
family care, caring for their loved ones, household duties, work duties, and their other medical conditions.

IPM physicians found navigating their patients' treatment through the healthcare system challenging while COVID-19 outbreak related restrictions were in effect. Only one third of IPM physicians work in an office-based setting, but a large proportion of providers perform their procedures in a hospital suite or ASCs (14). Even office-based proceduralists must utilize hospitals or ASCs for certain cases due to various medical or non-medical reasons. CMS elective surgery restrictions essentially resulted in decimation of IPM services nationally at hospitals and ASCs.

The same challenges were faced by hospitals and ambulatory care centers, all of which had to adapt their practice models in order to keep up-to-date with regulations, official guidance, and the vagaries of supply-and-demand as the nation's healthcare system struggled to allocate limited resources efficiently. One particularly hard-hit aspect of traditional care was the postoperative visit, which was largely dispensed with. Frontline clinicians made heroic efforts to navigate this unprecedented new medical landscape in a way that optimized safety and administered important treatments as much as possible. However, there is no doubt that during the pandemic many IPM patients may not have received optimal care because of COVID-19-related restrictions and concerns. Based on these simple facts, several key interventional procedures in subacute severe pain settings should be placed at a higher tier on the American College of Surgeons Elective Surgery Acuity Scale (ESAS) (37).

\subsection{IPM Resource Utilization}

When an interventional procedure is being considered for a pain patient, the clinical team must first evaluate not only the patient's relevant medical condition but his or her history with respect to COVID-19, including antigen or antibody testing and/or chest x-ray as deemed clinically appropriate by the ASIPP risk stratification table (3). Additionally, all the procedures must be performed within the framework of federal, state, and local regulations. Adequate PPE must be available for all in proximity to the patient. Note that in procedures in which the patient may be intubated or extubated, there is a strong probability of aerosolization. If general anesthesia is required, it should be induced and the patient intubated by an experienced healthcare professional; intubation should be carried out using rapid-sequence induction with video-laryngoscopy and minimal use of bag-mask ventilation. After general anesthesia, the patient should be extubated using airborne PPE. Following surgery, the patient should wear a surgical mask and receive high-flow oxygen $(\sim 6 \mathrm{~L} / \mathrm{min})$ to reduce the risk of aerosolization.

Regional anesthesia is not considered to cause a high degree of aerosolization, so droplet precautions need not be as stringent with this type of anesthesia. If regional anesthesia is utilized, all precautions should be taken to help minimize the risk of emergency conversion to general anesthesia during the procedure (34). Ultrasound may be used for guidance of peripheral nerve blocks but care should be taken to shield the equipment with disposable coverings (34).

During any procedure carried out in the COVID-19 era, it is important to minimize the presence of equipment in the room and protect what remains as much as possible with disposable coverings. While adequate clinical staff is needed, the fewer people involved the better; all personnel should wear appropriate PPE throughout the entire procedure (34).

Special care should be taken in moving the patient to and from the procedure. In some cases, the patient may need to recover in an airborne-infection isolation area (34).

\subsection{Definition of Medical Urgency of a Case}

In the context of IPM, medical urgency can be stratified by individual's clinical circumstances and by case. Certain types of cases can be safely postponed for a short duration and some may be postponed indefinitely with no harm to the patient. However, postponing other types of IPM procedures may subject the patient to risks, such as unrelieved pain, severe functional decline, the need to rely upon pharmacotherapy with its attendant risks, or the need to increase doses of opioids or NSAIDs. In many cases, there is an interplay of factors such that risks compete - the risk of exposure to viral infection versus the risk of untreated pain versus the risk of higher-than-usual drug doses.

Acute pain may be a symptom of a significant underlying disease and may be addressed as an emergency. In patients with subacute or chronic painful conditions, pain and concomitant severe functional limitations in addition to failure to manage it appropriately is associated with risks and may harm the patient. Patients with unrelieved chronic pain may be at risk for a host of other conditions such as memory loss (76), dementia (76), attention (77), depression $(78,79)$, functional deficits (79), anxiety (80), insomnia (81), suicidality (82), 
and others. Unrelieved chronic pain has been associated with early mortality (83). Poorly treated acute and chronic pain may lead to imprinting in the peripheral and central nervous system $(84,85)$.

Chronic pain in progressive diseases may be a symptom of a worsening underlying condition. Not only should this pain be treated, but it should also be regarded as a potential warning symptom that the disease may be getting worse or complications may be developing. For that reason, pain in progressive conditions should be closely monitored. Furthermore, the pain in patients at end of life can be severe, unremitting, and deserves adequate control (86).

In the COVID-19 area, the need to protect the patient from viral exposure must be weighed against the need for pain care. Numerous strategies have been proposed to mitigate the risk of viral transmission in the clinical setting, including PPE for clinicians, masks for patients, social distancing, hand hygiene, and so on. The risks of unrelieved moderate to severe pain are more challenging to reduce and reduction strategies, such as drug therapy or higher doses of drugs, carry with them risks that must be evaluated on a case-bycase basis. In some cases, postponing an IPM procedure may worsen the condition and may result in transforming a routine procedure today into a surgery or an emergency procedure next week.

Opioids may be prescribed to reduce pain in patients who must delay a needed IPM procedure. This is not an optimal strategy in that there are numerous opioid-associated function limiting side effects including drowsiness, somnolence, dizziness, pruritus, mental fog or confusion, constipation, headache, nausea, and others (87). These side effects can even be treatment limiting (88). While some symptoms will remit over time as tolerance develops, other symptoms such as opioid-induced constipation often persist throughout the duration of therapy (89). Beyond those adverse effects, there is a potential risk that the long-term use of opioids may result in opioid dependence and even opioid use disorder (90). There are established risk factors for opioid use disorder, such that certain patients must be regarded as being at elevated risk and possibly as inappropriate candidates for opioid treatment (91). While delayed IPM procedures may be managed safely in some patients with short-term or even long-term opioid therapy, this is not the optimal course of treatment for interventional pain patients and may be associated with serious safety concerns for certain patients.

\subsection{IPM Acuity Scale}

While nothing can replace clinical judgment for an individual case, the creation of an acuity or ranking scale may serve as a valuable tool for objective classification of patients to determine the need for IPM. Acuity scales can be crucial in helping to triage patients when resources are scarce and an orderly system is needed to assure all patients get appropriate care in as efficient a manner as possible (92). The determination as to whether a procedure is urgently or emergently indicated cannot be based solely on whether or not the procedure might be described as "elective" (93). The medical necessity for a procedure should be determined by an interventional pain specialist and may take multiple factors into account. Some factors include the patient's pain severity, physical incapacitation, underlying condition, comorbidities, disease progression, mental health status, response to alternative treatments, visits to other healthcare professionals, extent of analgesic management including the use of opioids and likely outcomes if the procedure is performed or delayed (93). Logistics and community safety may also play a role as healthcare resources may be limited (93). Blanket decisions on procedures should be avoided, as this is a dynamic environment with stark differences among regions and types of pain patients and their related functional impairments and differences in regional regulations.

For patients undergoing treatment at an ambulatory care center or other outpatient facilities, the $\mathrm{CDC}$ recommends that patients be contacted prior to visiting the center to be screened by phone for risk of COVID-19; following surgery, telephone follow-up can check on patients, verify medication adherence, and respond to questions the patients may have. If a person with known or suspected COVID-19 must be treated face-to-face, the patient should be asked to call before arriving at the facility so that the staff can be prepared (PPE, infection control practices) and so that the patient can be moved quickly into the system and receive care promptly. If patients or those accompanying them must wait in a waiting room, assure adequate distance between seats (six feet) and mark waiting lines to prevent patients from clustering together. In some cases, family and friends accompanying patients may have to be asked to wait outside. The CDC recommends that medical facilities waive any penalties they might normally impose on patients who miss appointments as patients may suddenly develop symptoms such that staying home is the appropriate and safe choice. 
Table 4. ASIPP guidance for triaging pain interventions with examples.

\begin{tabular}{|c|c|c|c|c|c|c|}
\hline & & Description & Locations & Examples & $\begin{array}{c}\text { Intervention } \\
\text { Examples }\end{array}$ & Timing \\
\hline 1 & Urgent & $\begin{array}{l}\text { Intermediate acuity } \\
\text { Unable to perform essential } \\
\text { ADLs } \\
\text { Progressive pain despite } \\
\text { conservative treatment } \\
\text { Possible future morbidity } \\
\text { Exacerbation of underlying } \\
\text { medical condition or may } \\
\text { proceed to surgery if not } \\
\text { treated with pain intervention } \\
\text { Psychosocial implications } \\
\text { Escalating opioid doses } \\
\text { Risk of chemical coping }\end{array}$ & $\begin{array}{l}\text { Office-based } \\
\text { Outpatient } \\
\text { ASC } \\
\text { Inpatient }\end{array}$ & $\begin{array}{l}\text { Failed noninterventional } \\
\text { management } \\
\text { New onset or exacerbation } \\
\text { of CRPS. } \\
\text { Acute exacerbation of } \\
\text { radiculopathy } \\
\begin{array}{l}\text { Degenerative or neurological } \\
\text { disease with walking } \\
\text { difficulty }\end{array} \\
\begin{array}{l}\text { Degenerative or neurological } \\
\text { disease with painful use of } \\
\text { upper extremities }\end{array} \\
\text { Intervention performed to } \\
\text { provide pain relief to allow } \\
\text { conservative management } \\
\text { such as physical therapy } \\
\text { Thoracic nerve blocks for rib } \\
\text { fractures } \\
\text { PDPH }\end{array}$ & $\begin{array}{l}\text { Epidural injections } \\
\text { Lumbar sympathetic } \\
\text { block } \\
\text { Epidural catheter in } \\
\text { cancer pain } \\
\text { Stellate ganglion block } \\
\text { Epidural blood patch } \\
\text { Intercostal nerve blocks } \\
\text { Vertebral augmentations } \\
\text { Facet joint interventions } \\
\text { Peripheral nerve blocks } \\
\text { pump refills } \\
\text { Other interventionsl }\end{array}$ & $\begin{array}{l}\text { Perform } \\
\text { procedure after } \\
\text { reasonable efforts } \\
\text { to postpone with } \\
\text { alternatives. } \\
\\
\text { Physician's } \\
\text { discretion. }\end{array}$ \\
\hline 2 & Emergency & $\begin{array}{l}\text { Severe acuity } \\
\text { Unable to perform most } \\
\text { ADLs due to severe physical } \\
\text { incapacitation } \\
\text { Rapidly progressive pain } \\
\text { Rapidly progressive decline in } \\
\text { function } \\
\text { Repeated ED visits due to pain } \\
\text { High probability of future } \\
\text { morbidity if procedure not } \\
\text { performed } \\
\text { Exacerbation of underlying } \\
\text { medical condition or may } \\
\text { proceed to surgery if not } \\
\text { treated with interventional pain } \\
\text { Development of an } \\
\text { unacceptable medical condition } \\
\text { unless the procedure is } \\
\text { performed } \\
\text { Pharmacologically and } \\
\text { otherwise unmanageable pain } \\
\text { Substantial risk of psychosocial } \\
\text { harm } \\
\text { Substantial risk of opioid } \\
\text { misuse, abuse and chemical } \\
\text { coping }\end{array}$ & $\begin{array}{l}\text { Office-based } \\
\text { Outpatient } \\
\text { ASC } \\
\text { Inpatient }\end{array}$ & $\begin{array}{l}\text { Impending severe drug } \\
\text { withdrawal } \\
\text { Disabling CRPS } \\
\text { Degenerative or neurological } \\
\text { disease with severe walking } \\
\text { inability } \\
\text { Degenerative or neurological } \\
\text { disease with severe inability to } \\
\text { use upper extremities } \\
\text { Alternative to pending spine } \\
\text { surgery, if appropriate } \\
\text { or } \\
\text { Any severe debilitating } \\
\text { disease that prevents patients } \\
\text { from performing activities of } \\
\text { daily living. }\end{array}$ & $\begin{array}{l}\text { Pump refills } \\
\text { Epidural injections } \\
\text { Facet joint interventions } \\
\text { Peripheral nerve blocks } \\
\text { Intercostal nerve blocks } \\
\text { Vertebral augmentation } \\
\text { Lumbar sympathetic } \\
\text { block } \\
\text { Stellate ganglion block } \\
\text { Other interventions }\end{array}$ & Do not postpone \\
\hline
\end{tabular}


Table 4 (connt.). ASIPP guidance for triaging pain interventions with examples.

\begin{tabular}{|c|c|c|c|c|c|c|}
\hline & & Description & Locations & Examples & $\begin{array}{c}\text { Intervention } \\
\text { Examples }\end{array}$ & Timing \\
\hline 3 & Elective & $\begin{array}{l}\text { Low acuity } \\
\text { Healthy patient } \\
\text { Stable } \\
\text { Able to perform ADL } \\
\begin{array}{l}\text { No meaningful functional } \\
\text { limitation }\end{array} \\
\text { Low risk to patient } \\
\begin{array}{l}\text { Low-risk options available } \\
\text { (home physical therapy, } \\
\text { pharmacological therapy) }\end{array}\end{array}$ & $\begin{array}{l}\text { Office-based } \\
\text { Outpatient } \\
\text { ASC } \\
\text { Inpatient }\end{array}$ & $\begin{array}{l}\text { Any pain condition that is } \\
\text { stable and can be managed } \\
\text { with alternatives }\end{array}$ & Any procedure & $\begin{array}{l}\mathrm{P} \text { o s t p o } \mathrm{n} \mathrm{e} \\
\text { procedure until } \\
\text { elective surgery } \\
\text { ban lifted }\end{array}$ \\
\hline
\end{tabular}

An acuity scale based on that modeled by the ESAS (94) was developed by the authors and appears as Table 4. It is important to keep in mind that although there is a tier classification, individuals often present to the pain clinician over a continuum.

\subsection{Relevance to Clinical Practice}

The use of ASIPP's IPM acuity classification will aid in the rapid, objective assessment of acute and chronic pain patients during the gradual phased re-opening following the COVID-19 shutdown and prepare the IPM specialty for "second waves", repeat shutdowns, future pandemics and many other similar meltdowns similar to what occurred during the COVID-19 pandemic. It must be stressed that an acuity scale is only a tool and constitutes many elements of a large mosaic that considers the patient holistically, that is, the patient's overall condition, including daily function, pharmacological drug use, comorbidities, risk factors, mental health, social risk factors and prognosis. Careful and consistent documentation is needed when reaching decisions about IPM triage. In this context, the use of templated tools can be helpful as it both accelerates and streamlines documentation to facilitate functional patient care without sacrificing accuracy.

Elective care describes those procedures that can safely and reasonably be postponed with little to no harm to the patient or in cases where performing the procedure would pose greater risk to the patient in terms of viral exposure than the delay of the interventional pain procedure. Urgent and emergency acuity classification for IPM patients is appropriate and may be carried out when the clinician assesses that a de- lay would result in unacceptable disease progression, intractable pain, disability, or suffering. Urgent and emergency cases can be performed when there is an assessment that delay would result in either unacceptable progression of disease, intractable pain, disability, or suffering. Optimally, the procedure should be performed under local anesthesia to conserve resources and minimize the chance of airway manipulation and super-spreading events that may ensue.

\subsection{Discussion}

As the American health care system returns to pre-COVID practice, the focus must be on providing health care services in a strategic manner, including to those patients suffering with chronic pain, using evidence-based methodologies in these and other relevant, reputable guidelines. ASIPP has developed risk stratification (3) based on patient comorbidities and this must be carried out to achieve optimal outcomes, moving forward, either during Phase I, II, or III or during resurgence with repeat of some of the phases. As usual, physician discretion, shared decision-making, following all the appropriate precautions including testing, with use of proper anesthetic techniques, is crucial, not only for quality, but also for patient safety and the safety of the physicians and other health care staff.

Although patients may challenge the risk assessment and stratification strategies to be undergone prior to procedures, the due attention will also provide comfort to patients that we are providing evidencebased or evidence-informed care. However, patients may also feel disappointment, when the indicated procedure is denied because their pain intervention 
belongs to a different category than surgical procedures. Consequently, it is crucial to provide the patient with appropriate informed consent, both to provide a good outline of key points in the risk assessment, to provide patients with take home material to review at their leisure, and to serve as clinical documentation. To a great extent, information provided, specifically based on evidence, and guidance, dispels confusion, reduces fear, and helps to improve not only the quality of care, but also patient satisfaction.

There are multiple limitations to the present guidelines. As we have seen, there is not a high level of evidence based on randomized controlled trials. Consequently, we utilized evidence informed decision making, which is practical and fits today's practices of real-world medicine. These recommendations were made during Phase II and III of re-opening, but by the writing of this manuscript, significant resurgence has been noted in multiple states, with Texas already stopping the elective surgical procedures.

\subsection{Conclusion}

The COVID-19 pandemic has created unprecedented challenges in IPM that need not culminate in unnecessary suffering for pain patients. As facilities and society gradually re-open, a triage system based on an acuity metric is needed for the appropriate care of patients based on their clinical need, safety, and status oflocal healthcare facilities. Many IPM procedures cannot be indefinitely postponed, although it is often possible to briefly delay a procedure without adverse consequences. Chronic pain exacerbations are associated with marked functional declines and treatment risks of alternative treatment modalities must be considered with the concern that they deserve. Clinicians must holistically assess patients, local healthcare resources, and weigh the benefits and risks of a procedure against the risks of exposure to the COVID-19 virus at all times.

\section{Author Contributions}

The concept was developed and the study was designed by the ASIPP Task Force at the request of ASIPP Board of Directors.

All authors contributed to preparation to the manuscript, reviewed, and approved the content with final version.

\section{Acknowledgments}

The authors would like to acknowledge the assistance of Jo Ann LeQuang of Angleton, Texas, who assisted with formatting and preparation of the manuscript with the consent and direction of the authors. The authors also wish to thank Bert Fellows, MA, Director Emeritus of Psychological Services at Pain Management Centers of America, for manuscript review, and Tonie M. Hatton and Diane E. Neihoff, transcriptionists, for their assistance in preparation of this manuscript. The authors would like to thank the editorial board of Pain Physician for review and criticism in improving the manuscript.

\section{Disclosures}

Dr. Shah is a consultant for Masimo Corporation and a speaking consultant for Allergan Corporation.

Dr. Kaye is a speaker for Merck.

Dr. Abd-Elsayed is a consultant for Medtronic, StimWave, and Avanos.

Dr. Hirsch is a consultant for Medtronic and Senior Affiliate Research Fellow at the Neiman Policy Institute.

Dr. Datta receives research support from Sucampo Pharmaceuticals and an honorarium from Smith and Nephew

Dr. Nampiaparampil is a speaker for AbbVie.

\section{Author Affiliation}

Christopher Gharibo, MD

Dr. Gharibo is Medical Director of Pain Medicine, NYU Langone Health, Associate Professor of Anesthesiology, Perioperative Care \& Pain Medicine, and Associate Professor of Orthopedics, NYU School of Medicine, New York, NY, USA.

cgharibo@usa.net

Amit Sharma, MD

Dr. Sharma is Chairman, Division of Pain Management, Good Samaritan Hospital Medical Center, West Islip, NY; Director of Interventional Spine and Pain Medicine, SpineCare Long Island, Plainview, NY amit1881@me.com

Amol Soin, MD

Dr. Soin is Medical Director, Ohio Pain Clinic, and Clinical Assistant Professor of Surgery at Wright State University, Dayton, OH, USA.

drsoin@gmail.com

Shalini Shah, MD

Dr. Shah is Vice-Chair and Enterprise Director of Pain Services, Department of Anesthesiology \& Perioperative Care, University of California Irvine, Orange, CA shahshalini@gmail.com

Sudhir Diwan, MD 
Dr. Diwan is President, Park Avenue Spine and Pain, and Associate Clinical Professor, Albert Einstein College of Medicine, New York, NY, USA

sudhir.diwan63@gmail.com

Ricardo Buenaventura, MD

Dr. Buenaventura is Medical Director, Pain Relief of Dayton, Centerville, $\mathrm{OH}$, and Clinical Associate Professor, Department of Surgery, Wright State University School of Medicine, Dayton, $\mathrm{OH}$.

rbuena@sbcglobal.net; dr.rbuena@gmail.com

Devi E. Nampiaparampil, MD

Dr. Nampiaparampil is Medical Director, Metropolis Pain Medicine, and Associate Professor, Rehabilitation Medicine, New York University School of Medicine, New York, NY.

devichechi@gmail.com

Steve M. Aydin, DO

Dr. Aydin is Clinical Assistant Professor of PM\&R, Zucker School of Medicine at Hofstra Northwell Health, Manhasset, NY, USA and Chief of PM\&R and Interventional Pain Management, Kayal Orthopaedic Centers, PC, Glen Rock, NJ, USA

steve.aydin@gmail.com

Sanjay Bakshi, MD

Dr. Bakshi is an interventional pain management physician at Lenox Hill Hospital, New York, NY, USA

drbakshi58@gmail.com

Salahadin Abdi, MD, PhD

Dr. Abdi is Tenured Professor and Chair, Department of Pain Medicine, University of Texas, MD Anderson Cancer Center, Houston, TX.

SAbdi@mdanderson.org

Sachin "Sunny" Jha, MD, MS

Dr. Jha is Assistant Clinical Professor of Anesthesiology, University of Southern California, Los Angeles, CA, USA

sunnyjha@gmail.com

Harold J. Cordner, MD

Dr. Cordner is with Florida Pain Management Associates, Sebastian, FL; and Associate Clinical Professor Florida State University College of Medicine, Tallahassee, FL.

gassdoc@aol.com

Alan D. Kaye, MD, PhD

Dr. Kaye is Vice-Chancellor of Academic Affairs, Chief Academic Officer, and Provost, Professor of Anesthesiology and Pharmacology, Toxicology, and Neurosciences, Louisiana State University Health Sciences Center, School of Medicine, Shreveport, LA, Professor of Anesthesiology and Pharmacology, LSU School of
Medicine, New Orleans, LA, and Professor of Anesthesiology and Pharmacology, Tulane School of Medicine, New Orleans, LA

akaye@lsuhsc.edu, alankaye44@hotmail.com

Alaa Abd-Elsayed, MD

Dr. Abd-Elsayed is Medical Director, UW Health

Pain Services, and Associate Professor, Anesthesiology, University of Wisconsin School of Medicine and Public Health, Madison, WI, USA

alaawny@hotmail.com; abdelsayed@wisc.edu

Kenneth D. Candido, MD

Dr. Candido is Chairman, Department of Anesthesiology, Advocate Illinois Masonic Medical Center and Professor of Clinical Anesthesia and Clinical Surgery, University of Illinois College of Medicine, Chicago, IL, USA

kdcandido1@gmail.com; kdcandido@yahoo.com

Nebojsa Nick Knezevic, MD, PhD

Dr. Knezevic is Vice Chair for Research and Education; Department of Anesthesiology; Advocate Illinois Masonic Medical Center, Chicago, IL and Clinical Associate Professor, Department of Anesthesiology, and Clinical Associate Professor Department of Surgery, College of Medicine, University of Illinois, Chicago, IL, USA

nick.knezevic@gmail.com

Sairam Atluri, MD

Dr. Atluri is Medical Director, Tri-State Spine Care Institute, Cincinnati, $\mathrm{OH}$

saiatluri@gmail.com

Bradley W. Wargo, DO

Dr. Wargo is an Interventional Pain Management Physician, Crosstown Back \& Pain Institute, Baptist Regional Medical Center, Memphis, TN, and Adjunct Clinical Associate Professor, Kansas Health Science Center, Department of Anesthesiology and Pain Medicine, Wichita, KS, USA

drbwargo@gmail.com

Mahendra R. Sanapati, MD

Dr. Sanapati is Co-Director, Pain Management Centers of America, Evansville, IN

msanapati@gmail.com

Sukdeb Datta, MD

Dr. Datta is Medical Director, Datta Endoscopic Back Surgery and Pain Center and Professorial Lecturer, Department of Anesthesiology, Mount Sinai School of Medicine, New York, NY.

sukdeb@hotmail.com

Joshua A. Hirsch, MD

Dr. Hirsch is Vice Chair and Service Line Chief of Neurointerventional Radiology, Chief of Neurointer- 
ventional Spine, Massachusetts General Hospital and Harvard Medical School, Boston, MA.

jahirsch@mgh.harvard.edu

Laxmaiah Manchikanti, MD

Dr. Manchikanti is Co-Director, Pain Management Centers of America, Clinical Professor, Anesthesiology and Perioperative Medicine, University of Louisville, Louisville, KY, and Professor of AnesthesiologyResearch, Department of Anesthesiology, School of
Medicine, LSU Health Sciences Center, New Orleans and Shreveport, LA drlm@thepainmd.com

Kartic Rajput, MD PhD

Dr. Rajput is a Pain Management Physician with Sutter Gould Medical Foundation, Memorial Medical Center Modesto, Surgery Center Division, Sutter Tracy Community Hospital, Stockton, CA 


\section{References}

1. Jha SS, Shah S, Calderon MD, Soin A, Manchikanti L. The effect of COVID-19 on interventional pain management practices: A physician burnout survey. Pain Physician 2020; 23: S271-282.

2. Barnes M, Sax PE. Challenges of "Return to Work" in an ongoing pandemic. N Engl J Med 2020 June 18; Epub ahead of print.

3. Shah S, Diwan S, Soin A, et al. Evidence-informed risk mitigation and stratification during COVID-19 for return to interventional pain practice: American Society of Interventional Pain Physicians (ASIPP) guidelines. Pain Physician 2020; 23:S161-S182.

4. Centers for Disease Control and Prevention, Office of the White House. Guidelines: Opening Up America Again. https://www.whitehouse.gov/ openingamerica Accessed 6/29/2020

5. Manchikanti L, Kaye AD, Soin A, et al. Comprehensive evidence-based guidelines for facet joint interventions in the management of chronic spinal pain: American Society of Interventional Pain Physicians (ASIPP) guidelines. Pain Physician 2020; 23:S1-S27.

6. Navani A, Manchikanti L, Albers SL, et al. Responsible, safe, and effective use of biologics in the management of low back pain: American Society of Interventional Pain Physicians (ASIPP) guidelines. Pain Physician 2019; 22:S1-S74.

7. Kaye AD, Manchikanti L, Novitch $M B$, et al. Responsible, safe, and effective use of antithrombotics and anticoagulants in patients undergoing interventional techniques: American Society of Interventional Pain Physicians (ASIPP) guidelines. Pain Physician 2019; 22:S75-S128.

8. Dieleman JL, Cao J, Chapin A, et al. US health care spending by payer and health condition, 1996-2016. JAMA 2020; 323:863-884.

9. Institute of Medicine (IOM). Relieving Pain in America: A Blueprint for Transforming Prevention, Care, Education, and Research. The National Academies Press, Washington, DC, June 29, 2011.

www.iom.edu/ /media/Files/Report\%2o Files/2011/Relieving-Pain-in-America-ABlueprint-for-Transforming-PreventionCare-Education-Research/Pain\%20 Research\%202011\%20Report\%20Brief. pdf. Accessed 6/29/2020
10. Mokdad AH, Ballestros K, et al. US Burden of Disease Collaborators, The state of US health, 1990-2016: Burden of diseases, injuries, and risk factors among US states. JAMA 2018; 319:1444-1472.

11. Freburger JK, Holmes GM, Agans RP, et al. The rising prevalence of chronic low back pain. Arch Intern Med 2009; 169:251-258.

12. Blyth FM, Briggs AM, Schneider $\mathrm{CH}$, Hoy DG, March LM. The global burden of musculoskeletal pain-where to from here? Am J Public Health 2019; 109:35-40.

13. Centers for Medicare \& Medicaid Services, National Health Expenditure Fact Sheet.

https://www.cms.gov/ResearchStatistics-Data-and-Systems/ Statistics-Trends-and-Reports/ NationalHealthExpendData/NHE-FactSheet. Accessed 6/29/2020

14. Manchikanti L, Sanapati MR, Pampati V, Boswell MV, Kaye AD, Hirsch JA. Update on reversal and decline of growth of utilization of interventional techniques in managing chronic pain in the Medicare population from 2000 to 2018 . Pain Physician 2019; 22:521-536.

15. Manchikanti L, Sanapati J, Benyamin RM, Atluri S, Kaye AD, Hirsch JA. Reframing the prevention strategies of the opioid crisis: Focusing on prescription opioids, fentanyl, and heroin epidemic. Pain Physician 2018; 21:309-326.

16. Manchikanti L, Singh V, Benyamin RM, Kaye AD, Pampati V, Hirsch JA. Reframing Medicare physician payment policy for 2019: A look at proposed policy. Pain Physician 2018; 21:415-432.

17. Chakravarthy K, Manchikanti L, Kaye $A D$, Christo PJ. Reframing the role of neuromodulation therapy in the chronic pain treatment paradigm. Pain Physician 2018; 21:507-513.

18. Orhan C, Van Looveren E, Cagnie B, Mukhtar NB, Lenoir D, Meeus M. Are pain beliefs, cognitions, and behaviors influenced by race, ethnicity, and culture in patients with chronic musculoskeletal pain: A systematic review. Pain Physician 2018; 21:541-558.

19. Moride $Y$, Lemieux-Uresandi D, Castillon G, et al. A systematic review of interventions and programs targeting appropriate prescribing of opioids. Pain Physician 2019; 22:229-240.

20. Fischer B, Jones W, Vojtila L, Kurdyak
P. Patterns, changes, and trends in prescription opioid dispensing in Canada, 2005-2016. Pain Physician 2018; 21:219-228.

21. National Institute on Drug Abuse. Overdose death rates. August 2018 https://www.drugabuse.gov/relatedtopics/trends-statistics/overdose-deathrates. Accessed 6/29/2020

22. Seth P, Rudd RA, Noonan RK, Haegerich TM. Quantifying the epidemic of prescription opioid overdose deaths. Am J Public Health 2018; 108:500-502.

23. IQVIA Institute for Human Data Science Study. Medicine use and spending in the U.S. A review of 2018 and outlook for 2023. May 2019.

https://www.iqvia.com/insights/the-iqviainstitute/reports/medicine-use-andspending-in-the-us-a-review-of2018-and-outlook-to-2023. Accessed 6/29/2020

24. NIDA. Overdose Death Rates. National Institute on Drug Abuse website. January 29, 2019.

https://www.drugabuse.gov/related-topics/ trends-statistics/overdose-death-rates. Accessed 6/29/2020

25. Alexander GC, Stoller KB, Haffajee RL, Saloner B. An epidemic in the midst of a pandemic: Opioid use disorder and COVID-19. Ann Intern Med 2020 Apr 2. [Epub ahead of print]

26. Choinière $M$, Dion $D$, Peng $P$, et al. The Canadian STOP-PAIN project - Part 1: Who are the patients on the waitlists of multidisciplinary pain treatment facilities? Can J Anaesth 2010; 57:539-548.

27. Eccleston C, Blyth FM, Dear BF, et al. Managing patients with chronic pain during the COVID-19 outbreak: considerations for the rapid introduction of remotely supported (eHealth) pain management services. Pain 2020; 161:889-893.

28. Chang HY, Daubresse M, Kruszewski SP, Alexander GC. Prevalence and treatment of pain in EDs in the United States, 2000 to 2010. Am J Emerg Med 2014; 32:421-431.

29. Smith TJ, Staats PS, Deer $T$, et al. Randomized clinical trial of an implantable drug delivery system compared with comprehensive medical management for refractory cancer pain: impact on pain, drug-related toxicity, and survival. J Clin Oncol 2002; 
20:4040-4049.

30. Dowell D, Haegerich TM, Chou R. CDC guideline for prescribing opioids for chronic pain--United States, 2016. MMWR Recomm Rep 2016; 65:1-49.

31. Centers for Medicare and Medicaid Services. Non-Emergent, Elective Medical Services, and Treatment Recommendations. Centers for Medicare and Medicaid Services, https://www.cms.gov/files/document/ cms-non-emergent-elective-medicalrecommendations.pdf. Published 2020. Updated April 7, 2020. Accessed June 15, 2020.

32. Centers for Disease Control and Prevention. Framework for Healthcare Systems Providing Non-COVID-19 Clinical Care During the COVID-19 Pandemic. Centers for Disease Control and Prevention. Published 2020 Updated May 12, 2020. https://www. cdc.gov/coronavirus/2019-ncov/hcp/ framework-non-COVID-care.html. Accessed June 29, 2020.

33. Shanthanna $\mathrm{H}$, Strand $\mathrm{NH}$, Provenzano DA, et al. Caring for patients with pain during the COVID-19 pandemic: consensus recommendations from an international expert panel. Anaesthesia 2020; 75:935-944

34. Uppal V, Sondekoppam RV, Landau R, El-Boghdadly K, Narouze S, Kalagara HKP. Neuraxial anaesthesia and peripheral nerve blocks during the COVID-19 pandemic: a literature review and practice recommendations. Anaesthesia 2020 April 28; Epub ahead of print.

35. Yeoh CB, Lee KJ, Rieth EF, et al. COVID-19 in the cancer patient. Anesth Analg 2020; 131:16-23

36. Cortiula F, Pettke A, Bartoletti M, Puglisi F, Helleday T. Managing COVID-19 in the oncology clinic and avoiding the distraction effect. Ann Oncol2O2O; 31:553-555.

37. Mouton C, Hirschmann MT, Ollivier M, Seil R, Menetrey J. COVID-19 - ESSKA guidelines and recommendations for resuming elective surgery. J Exp Orthop 2020; 7:28.

38. Kaye K, Paprottka F, Escudero R, et al. Elective, non-urgent procedures and aesthetic surgery in the wake of SARSCOVID-19: Considerations regarding safety, feasibility and impact on clinical management. Aesthetic Plast Surg 2020;
14:1-29.

39. Graham R, Mancher M, Wolman DM, Greenfield S, Steinberg E (eds); Committee on Standards for Developing Trustworthy Clinical Practice Guidelines; Institute of Medicine. Clinical Practice Guidelines We Can Trust. The National Academies Press, Washington, DC, 2011.

40. National Guideline Clearinghouse Extent Adherence to Trustworthy Standards (NEATS) instrument. www.ncbi.nlm.nih.gov/pubmedhealth/ PMHoo79458/ Accessed 5/28/2020

41. Harris RP, Helfand $M$, Woolf $\mathrm{SH}$, et al; Methods Work Group, Third US Preventive Services Task Force. Current methods of the US Preventive Services Task Force. Am ] Prevent Med 2001; 20:21-35.

42. Manchikanti L, Falco FJE, Benyamin RM, Kaye AD, Boswell MV, Hirsch JA. A modified approach to grading of evidence. Pain Physician 2014; 17:E319-E325.

43. Woodbury MG, Kuhnke JL. Evidencebased practice vs. evidence-informed practice: What's the difference? Wound Care Canada, 2014; 12:26-29.

44. Estabrooks CA. Will evidence-based nursing practice make practice perfect? Can J Nurs Res 1998; 30:15-36.

45. Miles A, Loughlin M. Models in the balance. Evidence-based medicine versus evidence-informed individualized care. J Eval Clin Pract 2011; 17:531-536.

46. World Health Organization, EvidenceInformed Policy Network. EVIPNet in action: 10 years, 10 stories.

www.who.int/evidence/en/ Accessed $6 / 29 / 2020$

47. Canadian Institutes of Health Research (CIHR). Introduction to evidenceinformed decision making.

https://cihr-irsc.gc.ca/e/45245.html Accessed 6/29/2020

48. Wahezi S, Gonzalez D, Yerra S, et al. Telemedicine during COVID and beyond: A practical guide and best practices multidisciplinary approach for the musculoskeletal physical exam. Pain Physician 2020; 23:S2O5-S238.

49. Brico E. Fatal overdose deaths soar in communities across the country amid COVID-19 pandemic. The Appeal, June 30, 2020.

https://theappeal.org/fatal-overdose- deaths-soar-in-communities-acrossthe-country-amid-covid-19-pandem ic/? fbclid=IwAR3 3 hati $40 \mathrm{KJKtCTRI}{ }_{3} \mathrm{O}_{2}$ K2tRtDbrjMgeuXPozdIXgo_6rWkiglpOk28tcw Accessed 7/10/2020

50. Centers for Disease Control and Prevention. Coronavirus Disease 2019 (COVID-19). Evidence used to update the list of underlying medical conditions that increase a person's risk of severe illness from COVID-19. Updated June 25, 2020.

www.cdc.gov/coronavirus/2019-ncov/ need-extra-precautions/evidence-table. html. Accessed July 5, 2020.

51. American Medical Association. Issue brief: Reducing barriers to vital pain medication during the COVID-19 pandemic.

https://www.ama-assn.org/system/ files/2020-05/issue-brief-reducingbarriers-vital-pain-medication.pdf Accessed 7/10/2020

52. American Medical Association. Issue brief: Reports of increases in opioidrelated overdose and other concerns during COVID pandemic. *Updated June 30, 2020.

https://www.ama-assn.org/system/ files/2020-07/issue-brief-increases-inopioid-related-overdose.pdf Accessed 7/10/2020

53. Wan W, Long H. 'Cries for help': Drug overdoses are soaring during the coronavirus pandemic. The Washington Post, July 1, 2020.

/ ww w. washington post.com/ health/2020/07/01/coronavirus-drugoverdose/ Accessed 7/10/2020

54. Ingersoll A. COVID-19 cited in spike of opioid overdoses. InvestigatePost, May 21, 2020.

https://www.investigativepost. org/2020/05/21/covid-19-cited-inspike-of-opioid-overdoses/ Accessed 7/10/2020

55. Dasgupta N, Beletsky L, Ciccarone D. Opioid crisis: No easy fix to its social and economic determinants. Am J Public Health 2018; 108:182-186.

56. Sanchez M, Eldeib D. Overdose deaths have skyrocketed in Chicago, and the coronavirus pandemic may be making it worse. ProPublica Illinois, May 30, 2020. Accessed 7/10/2020

https://www.propublica.org/article/ overdose-deaths-have-skyrocketed- 
in-chicago-and-the-coronaviruspandemic-may-be-making-it-worse

57. Anson P. Gabapentinoids involved in a third of overdoses in Scotland. Pain News Network, July 15, 2020.

https://www.painnewsnetwork.org/ stories/category/Pain+Medication Accessed 07/15/2020.

58. Grinspoon P. A tale of two epidemics: When COVID-19 and opioid addiction collide. Harvard Health Publishing, April 20, 2020.

www.health.harvard.edu/blog/atale-of-two-epidemics-whencovid-19-and-opioid-addictioncollide-2020042019569 Accessed 7/10/2020

59. Dubey S, Biswas P, Ghosh R, et al. Psychosocial impact of COVID-19. Diabetes Metab Syndr; 14:779-788.

6o. Volkow N. COVID-19: Potential implications for individuals with substance use disorders. National Institute on Drug Abuse, April 6, 2020. www.drugabuse.gov/about-nida/ noras-blog/2020/04/covid-19-potentialimplications-individuals-substanceuse-disorders Accessed 7/10/2020

61. Heath C, Sommerfield A, von UngernSternberg BS. Resilience strategies to manage psychological distress among healthcare workers during the COVID-19 pandemic: A narrative review. Anaesthesia 2020;10.

62. Dubey MJ, Ghosh R, Chatterjee S, Biswas P, Chatterjee S, Dubey S. COVID-19 and addiction. Diabetes Metab Syndr 2020; 14:817-823.

63. Becker WC, Fiellin DA. When epidemics collide: Coronavirus disease 2019 (COVID-19) and the opioid crisis. Ann Intern Med 2020; 173:59-60.

64. Lozada C. How fighting one pandemic can deepen another. The Washington Post, May 1, 2020.

https://www.washingtonpost.com/ outlook/2020/05/01/how-fightingone-pandemic-can-deepen-another/ Accessed 7/10/2020

65. Cox C, Kamal R, McDermott D. How have healthcare utilization and spending changed so far during the coronavirus pandemic? Health System Tracker, May 29, 2020.

https://www.healthsystemtracker.org/ chart-collection/how-have-healthcareutilization-and-spending-changedso-far-during-the-coronaviruspandemic/\#item-start Accessed
7/10/2020

66. Case A, Deaton A. Rising morbidity and mortality in midlife among white non-Hispanic Americans in the 21st century. Proc Natl Acad Sci U S A 2015; 112:15078-15083.

67. Pollard EM, Lamer TJ, Moeschler SM, et al. The effect of spinal cord stimulation on pain medication reduction in intractable spine and limb pain: a systematic review of randomized controlled trials and meta-analysis. J Pain Res 2019; 12:1311-1324.

68. Plein LM, Rittner HL. Opioids and the immune system - friend or foe. $\mathrm{Br} J$ Pharmacol 2018; 175:2717-2725.

69. Page GG. The immune-suppressive effects of pain. Adv Exp Med Biol 2003; 521:117-125.

70. Abdul AJ, Ghai B, Bansal D, Sachdeva N, Bhansali A, Dhatt SS. Hypothalamic pituitary adrenocortical axis suppression following a single epidural injection of methylprednisolone acetate. Pain Physician 2017; 20:E991-E1001.

71. Knezevic NN, Manchikanti L, Urits I, et al. Lack of superiority of epidural injections with lidocaine with steroids compared to without steroids in spinal pain: A systematic review and meta-analysis. Pain Physician 2020; 23:S239-S270.

72. Manchikanti L, Kosanovic R, Vanaparthy $\mathrm{R}$, et al. Steroid distancing in interventional pain management during COVID-19 and beyond: Safe, effective and practical approach. Pain Physician 2020; 23:S319-S352.

73. Manchikanti L, Knezevic NN, Parr A, Kaye AD, Sanapati M, Hirsch JA. Does epidural bupivacaine with or without steroids provide long-term relief? A systematic review and meta-analysis. Curr Pain Headache Rep 2020; 24:26.

74. Lee JH, Shin KS, Park SJ, et al. Comparison of clinical efficacy between transforaminal and interlaminar epidural injections in lumbosacral disc herniation: A systematic review and meta-analysis. Pain Physician 2018; 21:433-448.

75. Lee $\mathrm{JH}, \operatorname{Kim} \mathrm{DH}, \operatorname{Kim} \mathrm{DH}$, et al. Comparison of clinical efficacy of epidural injection with or without steroid in lumbosacral disc herniation: A systematic review and meta-analysis. Pain Physician 2018; 21:449-468.

76. Whitlock EL, Diaz-Ramirez LG, Glymour MM, Boscardin WJ, Covinsky KE, Smith AK. Association between persistent pain and memory decline and dementia in a longitudinal cohort of elders. JAMA Intern Med 2017; 177:1146-1153.

77. van der Leeuw G, Leveille SG, Dong $Z$, et al. Chronic pain and attention in older community-dwelling adults.] Am Geriatr Soc 2018; 66:1318-1324.

78. Sheng J, Liu S, Wang Y, Cui R, Zhang $X$. The link between depression and chronic pain: neural mechanisms in the brain. Neural Plast 2017; 2017:9724371.

79. IsHak WW, Wen RY, Naghdechi L, et al. Pain and depression: A systematic review. Harv Rev Psychiatry 2018; 26:352-363.

8o. Elbinoune I, Amine B, Shyen S, Gueddari S, Abouqal R, Hajjaj-Hassouni N. Chronic neck pain and anxietydepression: prevalence and associated risk factors. Pan Afr Med J 2016; 24:89.

81. Nijs J, Mairesse O, Neu D, et al. Sleep disturbances in chronic pain: neurobiology, assessment, and treatment in physical therapist practice. Phys Ther 2018; 98:325-335.

82. Racine M. Chronic pain and suicide risk: A comprehensive review. Prog Neuropsychopharmacol Biol Psychiatry. 2018; 87:269-280.

83. Da Silva JAP, Geenen R, Jacobs JWG. Chronic widespread pain and increased mortality: biopsychosocial interconnections. Ann Rheum Dis 2018; 77:790-792.

84. Malfliet A, Coppieters I, Van Wilgen $P$, et al. Brain changes associated with cognitive and emotional factors in chronic pain: A systematic review. Eur ] Pain 2017; 21:769-786.

85. Mitsi V, Zachariou V. Modulation of pain, nociception, and analgesia by the brain reward center. Neuroscience 2016; 338:81-92.

86. Lewis Ramos V, Eti S. Assessment and management of chronic pain in the seriously ill. Prim Care 2019; 46:319-333.

87. Mercadante S. Opioid analgesics adverse effects: The other side of the coin. Curr Pharm Des 2019; 25:3197-3202.

88. Fuggle N, Curtis E, Shaw S, et al. Safety of opioids in osteoarthritis: Outcomes of a systematic review and metaanalysis. Drugs Aging 2019; 36:129-143.

89. Farmer AD, Drewes AM, Chiarioni G, et al. Pathophysiology and management of opioid-induced constipation: European expert consensus statement. United European Gastroenterol ] 2019; 7:7-20.

90. Dowell D, Haegerich TM, Chou R. CDC 
Guideline for prescribing opioids for chronic pain--United States, 2016. JAMA 2016; 315:1624-1645.

91. Webster LR. Risk factors for opioid-use disorder and overdose. Anesth Analg 2017; 125:1741-1748.

92. Fong RY, Glen WSS, Mohamed Jamil AK, Tam WWS, Kowitlawakul Y. Comparison of the emergency severity index versus the patient acuity category scale in an emergency setting. Int Emerg Nurs 2018; 41:13-18.

93. American College of Surgeons. COVID-19: Guidance for triage of non-emergent surgical procedures. American College of Surgeons. March
17, 2020.

https://www.facs.org/covid-19/clinicalguidance/triage. Accessed June 17, 2020.

94. Siddiqui S. Elective Surgery Acuity Scale. American College of Surgeons. Published 2020.

https://www.facs.org/covid-19/clinicalguidance/triage. Accessed June 17, 2020. 
